\title{
Tear fluid signs associated with filtration blebs, as demonstrated by three-dimensional anterior segment optical coherence tomography
}

This article was published in the following Dove Press journal:

Clinical Ophthalmology

17 April 2014

Number of times this article has been viewed

\author{
Sachi Kojima \\ Toshihiro Inoue \\ Takahiro Kawaji \\ Hidenobu Tanihara \\ Department of Ophthalmology, \\ Faculty of Life Sciences, Kumamoto \\ University, Chuo-ku, Kumamoto, Japan
}

Correspondence: Toshihiro Inoue,

Department of Ophthalmology,

Faculty of Life Sciences,

Kumamoto University, I-I-I Honjo,

Chuo-ku, Kumamoto, Japan

Tel $+8 \mid 963735247$

Fax +8I 963735249

Email noel@da2.so-net.ne.jp
Purpose: To determine the clinical features of tear fluid signs associated with filtration blebs via three-dimensional anterior segment optical coherence tomography (3D AS-OCT).

Methods: In total, 152 eyes (130 patients) with glaucoma that underwent trabeculectomy with mitomycin $\mathrm{C}$ were evaluated retrospectively. We investigated tear fluid signs associated with filtration blebs, using 3D AS-OCT with custom software, and compared the findings of lower tear meniscus. We also analyzed postoperative intraocular pressure and the bleb parameters of filtration blebs between eyes with and without tear fluid signs.

Results: We found tear fluid signs associated with filtration blebs in 45 (30\%) of 152 eyes. The mean postoperative intraocular pressure of the eyes with the tear fluid sign in a filtration bleb was significantly lower than that in eyes without the tear fluid sign $(P<0.001)$. Blebs with tear fluid signs have more frequent identifiable filtration openings, greater total height, increased fluid-filled cavity height, and less wall intensity compared with blebs without these signs.

Conclusion: We identified tear fluid signs in AS-OCT images on or along filtration blebs that depended on bleb morphology. The occurrence of these signs may be related to the presence of functional blebs, which may thereby control postoperative intraocular pressure.

Keywords: filtration bleb, trabeculectomy, 3D AS-OCT, tear fluid sign

\section{Introduction}

Glaucoma is a leading cause of blindness globally, and reducing intraocular pressure (IOP) is the key to glaucoma management according to several large-scale clinical trials. ${ }^{1}$ Among the known IOP-lowering treatments, trabeculectomy is regarded as the standard surgical modality in cases refractory to medical and/or laser treatments. Reducing the IOP is related to the formation and maintenance of filtration blebs, and filtration blebs have been assessed clinically, using many imaging methods, such as slit-lamp examination, ultrasound biomicroscopy, and anterior segment photography. ${ }^{2-7}$ Newer imaging technologies include optical coherence tomography (OCT), which is a useful tool for investigating the characteristics of filtration blebs. ${ }^{8-12}$ Among the clinically applied OCT devices, three-dimensional anterior segment OCT (3D AS-OCT) is useful for identifying aqueous outflow channels and determining the morphology of the entire bleb (internal and external). ${ }^{13-15}$

In our previous case series of patients who underwent bleb revision, we found that filtration openings could be identified using preoperative $3 \mathrm{D}$ AS-OCT. ${ }^{16}$ Therefore, we believe that 3D AS-OCT is useful for devising a strategy for postoperative management of filtration blebs created by trabeculectomy. In our investigation of the characteristics of filtration bleb surfaces and walls, we observed minor tear-fluid-like findings in 3D 
AS-OCT images related to the surface on or along filtration blebs. However, these findings were not identical to those of the known tear meniscus in terms of their length and localization, and differentiating tear fluid signs from the thin epithelium (and subepithelial connective tissue) on filtration blebs is important in clinical practice.

In this study, we report the clinical characteristics of tear fluid signs on or along filtration blebs, as demonstrated by 3D AS-OCT and newly developed custom software.

\section{Materials and methods Assessment of filtration blebs after trabeculectomy}

We included 152 eyes from 130 patients who underwent trabeculectomy with adjunctive use of mitomycin $\mathrm{C}$. This protocol was approved by the Institutional Review Board at Kumamoto University in Japan, and the study was performed in compliance with the tenets of the Declaration of Helsinki. We retrospectively reviewed the medical records of these patients with regard to sex, age, eye laterality, etiology of glaucoma, IOP, history of previous intraocular surgeries, and design of the conjunctival incision for trabeculectomy. Among the 152 eyes, 47 had undergone cataract surgery (phacoemulsification and implantation of an intraocular lens) before trabeculectomy. Trabeculectomy was performed with phacoemulsification in 7 eyes; the remaining 145 eyes had undergone trabeculectomy alone.

The ocular surface and the internal structures of the filtration blebs were assessed by 3D AS-OCT (Casia; Tomey, Nagoya, Japan): $\leq 10 \mu \mathrm{m}$ (in tissue) axial resolution, $\leq 30 \mu \mathrm{m}$ (in tissue) transverse resolution, $8 \times 8 \mathrm{~mm}$ (scan type: Bleb) imaging field size, and 30,000 scans/second at an A-scan rate. For this assessment, a patient was asked to look down and the examiner used a finger to gently elevate the upper lid to expose the filtration bleb. The scan area was chosen to include the entire scleral flap and bleb. At least two scanning directions were used for each bleb, as horizontal and vertical rasters, and each raster consisted of 512 scans. We obtained a full 3D image of the filtration bleb using this method (Figure 1).

\section{Assessment of filtration blebs and the tear fluid sign}

We used slit-lamp examinations and color photography of the anterior ocular segment to evaluate the appearance of blebs and then used 3D AS-OCT to assess internal bleb structures. On the basis of the appearance of blebs in color photographs of the anterior ocular segments, bleb wall transparencies were

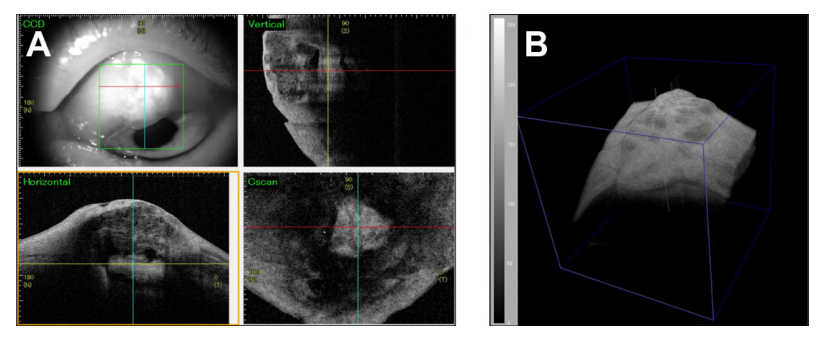

Figure I (A) Photographs (upper left) and vertical (upper right), horizontal (lower left), and C-scan (lower right) three-dimensional anterior segment optical coherence tomography (3D AS-OCT) images. Red and blue lines indicate horizontal and vertical AS-OCT axes, respectively. Yellow lines indicate the Z-axis of the AS-OCT data corresponding to the $\mathrm{C}$-scan image. The green square indicates the scan field $(8 \times 8 \mathrm{~mm})$. (B) Reconstructed 3D image of a bleb.

Abbreviation: CCD, charge-coupled device.

classified as high, moderate, or low when the scleral flap margin was clearly visible, partially visible, and invisible, respectively (Figure 2 ).

We used 3D AS-OCT and the associated software (Casia bleb assessment software, version 4.0L; Tomey) to measure bleb height, fluid-filled cavity height, bleb wall thickness, and intensity (optical density) of the bleb wall. We identified filtration openings by the presence of pits and/or troughs in fluid-filled cavities in both horizontal and vertical rasters, using the corresponding C-scan image of the scleral flap margins in the bleb, as described in our previous study. ${ }^{17}$

We selected a single cross-sectional image for each tear fluid sign, in which we observed the deepest fluid, from complete 3D images consisting of 512 scans. With the aid of the installed software, we measured the characteristics of the tear fluid signs: the thickness of the surface boundary signal, length of the cross-sectional surface, cross-sectional area, cross-sectional circumference, and depth of fluid (Figure 3A). We also assessed the lower tear meniscus of eight healthy volunteers by measuring the fluid characteristics with the aid of custom software as described earlier (Figure 3B). Last, we compared tear fluid signs associated with filtration blebs with lower tear meniscus signs.

At least three reviewers evaluated the complete $3 \mathrm{D}$ images of the internal structure of the filtration blebs and fluid signs and independently assessed the 3D AS-OCT images. When opinions among the reviewers differed, the majority decision was chosen.

\section{Statistical analysis}

Numerical data are presented as means \pm standard deviations (SD). Statistical analyses were performed using Student's $t$-test or the $\chi^{2}$ test. $P$-values lower than 0.05 were considered to indicate a significant difference. 

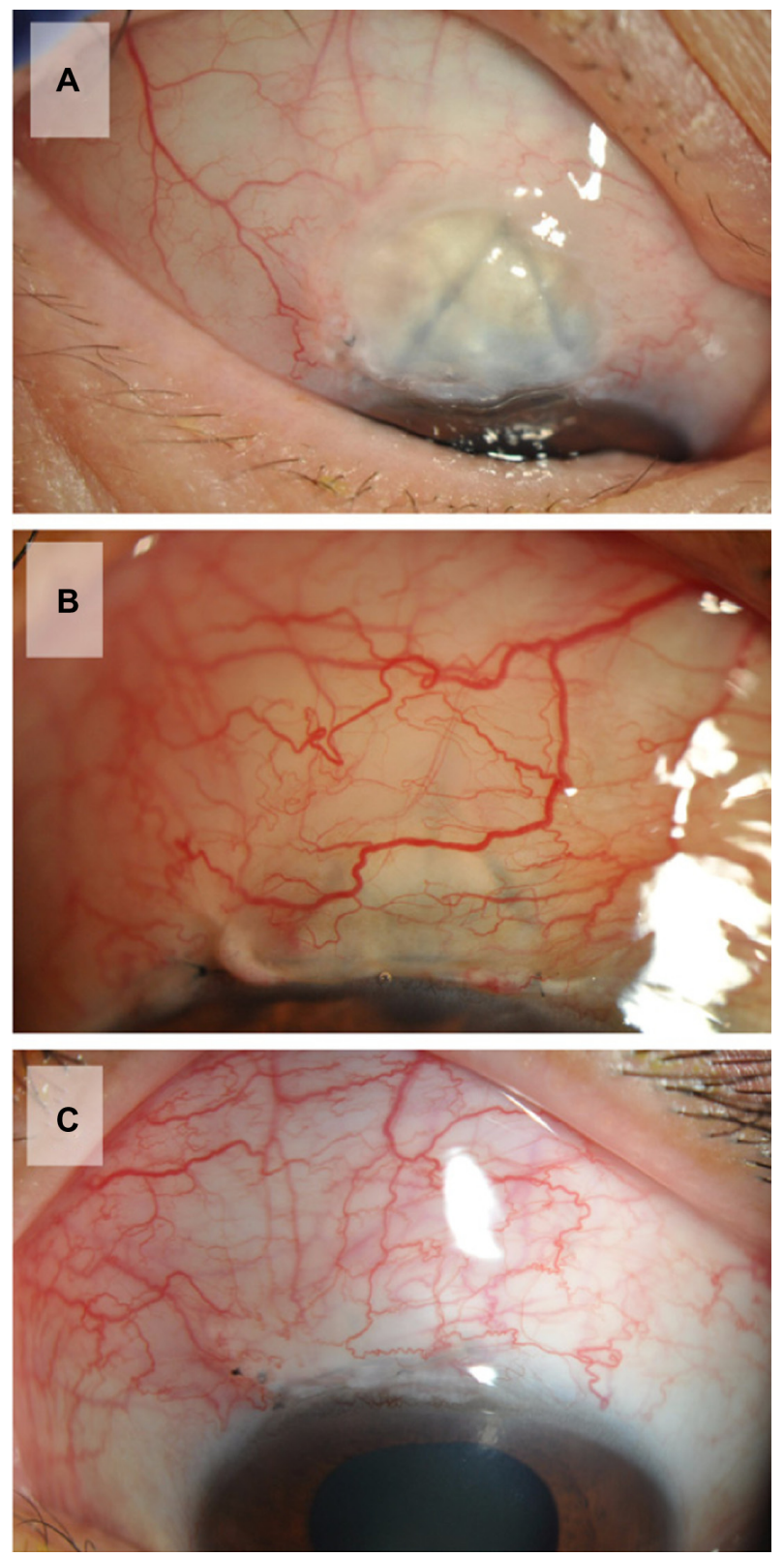

Figure 2 Representative color photos of blebs with bleb walls of high (A), moderate (B), and low (C) transparency. Bleb wall transparencies were classified as high, moderate, and low when the scleral flap margin was clearly visible, partially visible, and invisible, respectively.

\section{Results}

\section{Tear fluid sign with filtration bleb}

In $45(29.6 \%)$ of the 152 eyes, OCT images demonstrated tear fluid signs with filtration blebs. These signs occurred on or along elevated and/or bumpy blebs in all 45 eyes. In contrast, eyes with flat blebs showed no tear fluid signs.

We conducted a comparative study of the clinical backgrounds of the patients having eyes with tear fluid signs and those without the signs. In 45 eyes with tear fluid signs, the mean $( \pm \mathrm{SD})$ IOP value was $11.0 \pm 4.9 \mathrm{mmHg}$, which
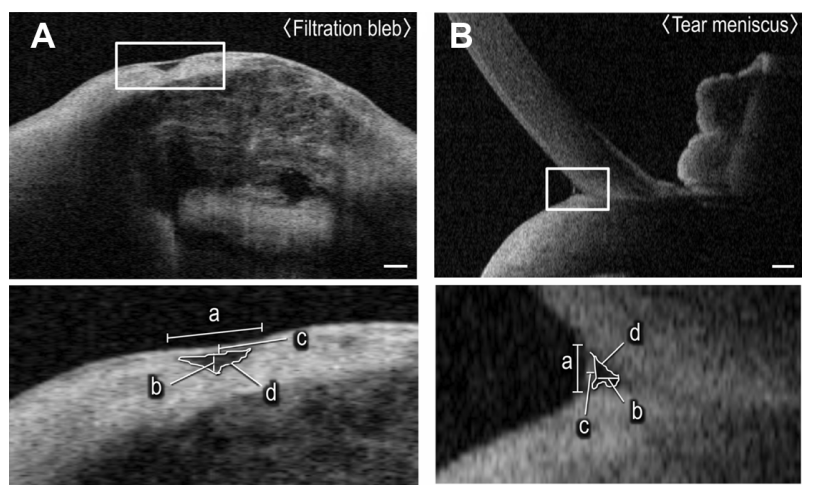

Figure 3 Measurements of $(\mathbf{A})$ a tear fluid sign on a filtration bleb and (B) a tear meniscus sign on a lower lid of a healthy volunteer in three-dimensional anterior segment optical coherence tomography (3D AS-OCT) images. Lower panels show enlarged images of areas in the white boxes in upper panels. We measured the characteristics of the tear fluid signs with the aid of custom software: length of the cross-sectional surface (a), depth of the fluid (b), thickness of the surface boundary signal (c), cross-sectional circumference (d), and cross-sectional area. Scale bars, $\mathrm{l} \mathrm{mm}$.

was significantly lower than that in the remaining 107 eyes without tear fluid signs associated with filtration blebs (16.0 $\pm 6.6 \mathrm{mmHg} ; P<0.001)$. A significant difference was observed for sex of the patients in the two groups $(P=0.038)$. In contrast, the two groups showed no significant differences in age, laterality, etiology of glaucoma, previous cataract surgery, or design of conjunctival incision (Table 1).

Color photograph assessments showed that 45 eyes with tear fluid signs had significantly more transparent filtration bleb walls compared with eyes without these signs $(P<0.001)$. In addition, filtration openings on the scleral flap were identified by 3D AS-OCT more frequently in eyes with tear fluid signs than in eyes without tear fluid signs $(P=0.010)$. Our quantitative analyses of the internal structures of filtration blebs showed that eyes with the tear fluid sign had more total bleb height $(P=0.005)$, more fluid-filled cavity height $(P=0.046)$, and lower intensity of the bleb wall $(P<0.001)$ compared with eyes without tear fluid signs. In contrast, no significant difference was observed in bleb wall thickness between the two groups (Table 2). Thus, our qualitative and quantitative studies suggest that bleb appearance is associated with the presence of tear fluid signs. In addition, the highly transparent blebs (15 eyes) in the photo-based classification had bleb walls of lower intensity, as measured by AS-OCT, compared with the other blebs (118.0 versus 148.5 optical density; $P=0.028$ ), whereas other bleb parameters in AS-OCT images were not different between the groups.

\section{Evaluation of the lower tear meniscus}

Our 3D AS-OCT measurements in eight healthy volunteers showed that the thickness of the surface boundary signal, depth 
Table I Clinical data of eyes with and without tear fluid signs after trabeculectomy with mitomycin $C$

\begin{tabular}{|c|c|c|c|}
\hline Variable & $\begin{array}{l}\text { With tear } \\
\text { fluid signs } \\
\text { (45 eyes) }\end{array}$ & $\begin{array}{l}\text { Without tear } \\
\text { fluid signs } \\
\text { (107 eyes) }\end{array}$ & $P$ \\
\hline Sex & & & 0.038 \\
\hline Male & $20(44.4 \%)$ & 67 (62.6\%) & \\
\hline Female & $25(55.6 \%)$ & $40(37.4 \%)$ & \\
\hline Age, years & & & 0.289 \\
\hline $\begin{array}{l}\text { Mean } \pm \text { standard } \\
\text { deviation }\end{array}$ & $67.4 \pm 12.3$ & $64.8 \pm 14.6$ & \\
\hline Range & $4 I-85$ & $17-90$ & \\
\hline Eye laterality & & & 0.214 \\
\hline Left & $26(57.8 \%)$ & $50(46.7 \%)$ & \\
\hline Right & $19(42.2 \%)$ & $57(53.3 \%)$ & \\
\hline Etiology of glaucoma & & & 0.920 \\
\hline Exfoliation glaucoma & $13(28.9 \%)$ & 32 (29.9\%) & \\
\hline $\begin{array}{l}\text { Primary open-angle } \\
\text { glaucoma }\end{array}$ & $12(26.7 \%)$ & $25(23.4 \%)$ & \\
\hline Uveitic glaucoma & $10(22.2 \%)$ & $23(21.5 \%)$ & \\
\hline $\begin{array}{l}\text { Neovascular } \\
\text { glaucoma }\end{array}$ & $5(11.1 \%)$ & $18(16.8 \%)$ & \\
\hline $\begin{array}{l}\text { Primary angle- } \\
\text { closure glaucoma }\end{array}$ & $3(6.7 \%)$ & $4(3.7 \%)$ & \\
\hline Other types & $2(4.4 \%)$ & $5(4.7 \%)$ & \\
\hline $\begin{array}{l}\text { Intraocular } \\
\text { pressure, } \mathrm{mmHg}\end{array}$ & & & $<0.001$ \\
\hline $\begin{array}{l}\text { Mean } \pm \text { standard } \\
\text { deviation }\end{array}$ & $11.0 \pm 4.9$ & $16.0 \pm 6.6$ & \\
\hline Range & $2.0-24.0$ & $1.0-47.0$ & \\
\hline $\begin{array}{l}\text { Previous cataract } \\
\text { surgery }\end{array}$ & & & 0.686 \\
\hline Yes (pseudophakia) & 15 (33.3\%) & $32(29.9 \%)$ & \\
\hline No (phakia) & $30(66.7 \%)$ & $75(70.1 \%)$ & \\
\hline Conjunctival flap & & & 0.708 \\
\hline Limbal base & 7 (I5.6\%) & $14(13.1 \%)$ & \\
\hline Fornix base & $35(77.8 \%)$ & $83(77.6 \%)$ & \\
\hline Unknown & $3(6.7 \%)$ & $10(9.3 \%)$ & \\
\hline
\end{tabular}

of fluid, length of cross-sectional surface, cross-sectional circumference, and cross-sectional area of the tear meniscus sign in the lower eyelid (mean $\pm \mathrm{SD}$ ) were $41.4 \pm 1.2 \mu \mathrm{m}$, $351.5 \pm 107.3 \mu \mathrm{m}, 178.8 \pm 56.3 \mu \mathrm{m}, 1092.1 \pm 395.3 \mu \mathrm{m}$, and $39.0 \pm 22.1 \times 10^{3} \mu \mathrm{m}^{2}$, respectively. From these observations, we believe these signals to be tear fluid signs with the following criteria: thickness of the surface boundary signal of about $40 \mu \mathrm{m}$; smooth and curved (to the tissue side) surface line, similar to a suspension bridge with underlying empty dark space; and localization of the sign on or near the dents and steep skirt on the ocular surface (Figure 3A).

\section{Comparison of tear fluid sign and lower tear meniscus}

The mean \pm SD thickness of the surface boundary signal of tear fluid signs was $42.3 \pm 3.1 \mu \mathrm{m}$, which was similar to that
Table 2 Bleb characteristics in eyes with and without tear fluid signs

\begin{tabular}{|c|c|c|c|}
\hline Variable & $\begin{array}{l}\text { With tear } \\
\text { fluid signs }\end{array}$ & $\begin{array}{l}\text { Without tear } \\
\text { fluid signs }\end{array}$ & $P$ \\
\hline $\begin{array}{l}\text { Bleb wall transparency } \\
\text { according to color } \\
\text { photographs }\end{array}$ & & & $<0.001$ \\
\hline Low & $10(22.2 \%)$ & $43(40.2 \%)$ & \\
\hline Moderate & 22 (48.9\%) & $62(57.9 \%)$ & \\
\hline High & $13(28.9 \%)$ & $2(1.9 \%)$ & \\
\hline $\begin{array}{l}\text { Presence of filtration } \\
\text { openings }\end{array}$ & & & 0.010 \\
\hline Yes & 43 (95.6\%) & $84(78.5 \%)$ & \\
\hline No & $2(4.4 \%)$ & $23(21.5 \%)$ & \\
\hline Total bleb height, mm & & & 0.005 \\
\hline $\begin{array}{l}\text { Mean } \pm \text { standard } \\
\text { deviation }\end{array}$ & I.II $17 \pm 0.457$ & $0.863 \pm 0.512$ & \\
\hline Range & $0.116-2.122$ & $0.075-2.805$ & \\
\hline $\begin{array}{l}\text { Fluid-filled cavity } \\
\text { height, mm }\end{array}$ & & & 0.046 \\
\hline $\begin{array}{l}\text { Mean } \pm \text { standard } \\
\text { deviation }\end{array}$ & $0.398 \pm 0.365$ & $0.270 \pm 0.356$ & \\
\hline Range & $0-1.460$ & $0-2.561$ & \\
\hline Bleb wall thickness, $\mathrm{mm}$ & & & 0.168 \\
\hline $\begin{array}{l}\text { Mean } \pm \text { standard } \\
\text { deviation }\end{array}$ & $0.7 I I \pm 0.443$ & $0.612 \pm 0.377$ & \\
\hline Range & $0.069-|.75|$ & $0.075-2.070$ & \\
\hline $\begin{array}{l}\text { Intensity of bleb wall, } \\
\text { optical density }\end{array}$ & & & $<0.001$ \\
\hline $\begin{array}{l}\text { Mean } \pm \text { standard } \\
\text { deviation }\end{array}$ & $121.73 \pm 47.23$ & $156.39 \pm 48.03$ & \\
\hline Range & $33.3 \mid-208.8$ & $29.44-234.6$ & \\
\hline
\end{tabular}

of the tear meniscus signs in the eight healthy volunteers (41.4 $\pm 1.2 \mu \mathrm{m}$; Table 3 ). In addition, the ranges of the values were similar in the two groups (33-48 and 39-43 $\mu \mathrm{m}$ ). In contrast, the depth of the fluid, length of the cross-sectional surface, cross-sectional circumference, and cross-sectional area of the tear fluid signs differed among the participants. Statistical analyses showed significant differences only in the length of cross-sectional surface of the tear fluid signs compared with the tear meniscus signs $(P=0.013)$, but not for other dimensions, probably because of the large SDs (Table 3).

\section{Discussion}

It is well known that maintenance and turnover of tear fluid on the ocular surface are quite important for protecting the cornea and conjunctiva while the eye is open. ${ }^{18-20}$ This information seems to agree with our clinical experience with glaucomatous eyes that have functional filtration blebs. In addition, Soong and Quigley reported that the most important factor predisposing to dellen formation was poor tear film integrity adjacent to the bleb. ${ }^{21}$ Because vulnerability 
Table 3 Characteristics of tear fluid signs and lower tear meniscus signs

\begin{tabular}{|c|c|c|c|}
\hline Variable & $\begin{array}{l}\text { Tear fluid } \\
\text { signs }\end{array}$ & $\begin{array}{l}\text { Tear meniscus } \\
\text { signs }\end{array}$ & $P$ \\
\hline $\begin{array}{l}\text { Thickness of surface } \\
\text { boundary signal, } \mu \mathrm{m}\end{array}$ & & & 0.397 \\
\hline Mean \pm standard deviation & $42.3 \pm 3.1$ & $4 I .4 \pm I .2$ & \\
\hline Range & $33-48$ & $39-43$ & \\
\hline $\begin{array}{l}\text { Length of cross-sectional } \\
\text { surface, } \mu \mathrm{m}\end{array}$ & & & 0.013 \\
\hline Mean \pm standard deviation & $769.8 \pm 451.3$ & $351.5 \pm 107.3$ & \\
\hline Range & $283-2,235$ & $23 I-500$ & \\
\hline $\begin{array}{l}\text { Cross-sectional area, } \\
\times 10^{3} \mu \mathrm{m}^{2}\end{array}$ & & & 0.367 \\
\hline Mean \pm standard deviation & $57.7 \pm 57.0$ & $39.0 \pm 22.1$ & \\
\hline Range & $16-357$ & $|8-7|$ & \\
\hline $\begin{array}{l}\text { Cross-sectional } \\
\text { circumference, } \mu \mathrm{m}\end{array}$ & & & 0.092 \\
\hline Mean \pm standard deviation & $|634.6 \pm 87| .4$ & $1092.1 \pm 395.3$ & \\
\hline Range & $632-4,702$ & $698-1,715$ & \\
\hline Depth of fluid, $\mu \mathrm{m}$ & & & 0.108 \\
\hline Mean \pm standard deviation & $|35.2 \pm 7| . \mid$ & $178.8 \pm 56.3$ & \\
\hline Range & $4 I-458$ & $124-262$ & \\
\hline
\end{tabular}

of the ocular surface to inflammatory disorders has been demonstrated in eyes with tear film dysfunction, ${ }^{22,23}$ tear film integrity is hypothesized to also be important for the conjunctiva in glaucomatous eyes with functional filtration blebs because serious visual loss may result from bleb infection and subsequent endophthalmitis. ${ }^{24,25}$ Thus, developing a safe and noninvasive method of assessing tear film integrity in eyes with functional filtration blebs is important. The recent development of AS-OCT has enabled information on internal bleb morphology to be obtained in a noninvasive and safe manner. ${ }^{9,10}$ In the present study, our observations showed that $3 \mathrm{D}$ AS-OCT is a safe and useful tool for examining the ocular surface and internal structures in eyes with functional filtration blebs.

We initiated this study because we had some cases with tear meniscus-like AS-OCT findings on and along filtration blebs. Wang et al reported detailed information on tear film and meniscus in human eyes obtained by AS-OCT. ${ }^{26,27}$ They demonstrated a mean tear film thickness of 4.9-6.8 $\mu \mathrm{m}$ that depended on blinking status. ${ }^{26}$ Because the resolution of OCT imaging is $10 \mu \mathrm{m}$, determining the exact tear film thickness in this narrow range on the central corneal surface is presumably difficult. In fact, to identify tear film on the central cornea by separating signals between the tear film and the corneal surface, Wang et al intentionally increased tear film thickness by means of topical administration of artificial tear fluid. ${ }^{26}$ In addition, the mean area of the lower tear meniscus in eyes with normal blinking was $26 \times 10^{3}-31 \times 10^{3} \mu \mathrm{m}^{2}{ }^{26}$ which is in agreement with our measurements immediately after eye opening $\left(39.0 \pm 22.1 \times 10^{3} \mu^{2}\right)$.

When we compared the tear fluid signs in eyes with filtration blebs with the tear meniscus signs in healthy volunteers, the OCT images showed a similar surface boundary signal thickness of 33-48 $\mu \mathrm{m}$. This similarity was expected because the surface boundary signal of the tear meniscus and tear fluid signs on the ocular surface are thought of as an artificial line indicating the transition phase of the emission light from the air to the fluid. In other words, we can measure the thickness of the surface boundary signal, but indeed, no "thickness" is found in the transition phase on the actual ocular surface. In contrast, other measurements, such as the length of the cross-sectional surface, cross-sectional area, cross-sectional circumference, and depth of tear fluid, varied depending on the morphology of the ocular surface.

Our statistical analyses showed significant differences in IOP levels, transparency of the bleb walls, total bleb height, fluid-filled cavity height, and bleb wall intensity in the filtration blebs. These findings also support our hypothesis that the morphology of the bleb is an important factor for determining the characteristics of the tear fluid signs on the conjunctival surface in eyes with elevated and functional filtration blebs. Because bleb appearance is reportedly associated with filtration function in eyes after trabeculectomy, our results in this study were in good agreement with those of previous clinical studies of the surgical outcome of trabeculectomy. ${ }^{2-7}$

The existence of the tear fluid sign on or along a filtration bleb may simply indicate retention of the tear on the bleb, depending on the bumpy structure of the filtration bleb. In this model, good IOP control is related to a bleb with bumpy structures, although the precise mechanism is unknown. In contrast, our recent study showed that the presence of transconjunctival oozing phenomena accompanied with a bleb wall of low intensity was associated with a reduction in IOP after trabeculectomy (unpublished data). Conceivably, the tear fluid sign may indicate the occurrence of transconjunctival oozing phenomena on the surface of the filtration bleb, and the existence of the tear fluid sign might relate to reduced postoperative IOP. Interestingly, a highly transparent bleb was observed more frequently in eyes with the tear fluid sign. Presumably, the high transparency reflected a thin and/or low-density bleb wall. Indeed, the bleb wall intensity measured by AS-OCT was lower in highly transparent blebs in the present study. 


\section{Conclusion}

We found tear fluid signs on or along filtration blebs in ASOCT images, and these signs depended on bleb morphology. In addition, the occurrence of tear fluid signs may be related to the presence of functional blebs, which may thereby control the IOP.

\section{Disclosure}

This work was supported, in part, by JSPS KAKENHI grant numbers 23390403, 23659814, and 23791994. The sponsor or funding organization had no role in the design or conduct of this research.

The authors report no other conflicts of interest in this work.

\section{References}

1. The Advanced Glaucoma Intervention Study (AGIS): 7. The relationship between control of intraocular pressure and visual field deterioration. The AGIS Investigators. Am J Ophthalmol. 2000;130(4):429-440.

2. Picht G, Grehn F. Classification of filtering blebs in trabeculectomy: biomicroscopy and functionality. Curr Opin Ophthalmol. 1998; 9(2):2-8.

3. Cantor LB, Mantravadi A, WuDunn D, Swamynathan K, Cortes A. Morphologic classification of filtering blebs after glaucoma filtration surgery: the Indiana Bleb Appearance Grading Scale. J Glaucoma. 2003;12(3):266-271.

4. Wells AP, Crowston JG, Marks J, et al. A pilot study of a system for grading of drainage blebs after glaucoma surgery. J Glaucoma. 2004;13(6):454-460.

5. Wells AP, Ashraff NN, Hall RC, Purdie G. Comparison of two clinical Bleb grading systems. Ophthalmology. 2006;113(1):77-83.

6. Sacu S, Rainer G, Findl O, Georgopoulos M, Vass C. Correlation between the early morphological appearance of filtering blebs and outcome of trabeculectomy with mitomycin C. J Glaucoma. 2003;12(5):430-435.

7. Yamamoto T, Sakuma T, Kitazawa Y. An ultrasound biomicroscopic study of filtering blebs after mitomycin C trabeculectomy. Ophthalmology. 1995;102(12):1770-1776.

8. Savini G, Zanini M, Barboni P. Filtering blebs imaging by optical coherence tomography. Clin Experiment Ophthalmol. 2005;33(5): 483-489.

9. Leung CK, Yick DW, Kwong YY, et al. Analysis of bleb morphology after trabeculectomy with Visante anterior segment optical coherence tomography. Br J Ophthalmol. 2007;91(3):340-344.

10. Singh M, Chew PT, Friedman DS, et al. Imaging of trabeculectomy blebs using anterior segment optical coherence tomography. Ophthalmology. 2007;114(1):47-53.
11. Nakano N, Hangai M, Nakanishi H, et al. Early trabeculectomy bleb walls on anterior-segment optical coherence tomography. Graefes Arch Clin Exp Ophthalmol. 2010;248(8):1173-1182.

12. Pfenninger L, Schneider F, Funk J. Internal reflectivity of filtering blebs versus intraocular pressure in patients with recent trabeculectomy. Invest Ophthalmol Vis Sci. 2011;52(5):2450-2455.

13. Miura M, Kawana K, Iwasaki T, et al. Three-dimensional anterior segment optical coherence tomography of filtering blebs after trabeculectomy. J Glaucoma. 2008;17(3):193-196.

14. Yasuno Y, Yamanari M, Kawana K, Oshika T, Miura M. Investigation of post-glaucoma-surgery structures by three-dimensional and polarization sensitive anterior eye segment optical coherence tomography. $\mathrm{Opt}$ Express. 2009;17(5):3980-3996.

15. Kawana K, Kiuchi T, Yasuno Y, Oshika T. Evaluation of trabeculectomy blebs using 3-dimensional cornea and anterior segment optical coherence tomography. Ophthalmology. 2009;116(5):848-855.

16. Kojima S, Inoue T, Kawaji T, Tanihara H. Filtration bleb revision guided by 3 -dimensional anterior segment optical coherence tomography. J Glaucoma. Epub January 31, 2013.

17. Inoue T, Matsumura R, Kuroda U, Nakashima K, Kawaji T, Tanihara H. Precise identification of filtration openings on the scleral flap by threedimensional anterior segment optical coherence tomography. Invest Ophthalmol Vis Sci. 2012;53(13):8288-8294.

18. Doane MG. Blinking and the mechanics of the lacrimal drainage system. Ophthalmology. 1981;88(8):844-851.

19. Tsubota K, Nakamori K. Effects of ocular surface area and blink rate on tear dynamics. Arch Ophthalmol. 1995;113(2):155-158.

20. Doane MG. Interactions of eyelids and tears in corneal wetting and the dynamics of the normal human eyeblink. Am J Ophthalmol. 1980;89(4): 507-516.

21. Soong HK, Quigley HA. Dellen associated with filtering blebs. Arch Ophthalmol. 1983;101(3):385-387.

22. Onguchi T, Dogru M, Okada N, et al. The impact of the onset time of atopic keratoconjunctivitis on the tear function and ocular surface findings. Am J Ophthalmol. 2006;141(3):569-571.

23. Enríquez-de-Salamanca A, Castellanos E, Stern ME, et al. Tear cytokine and chemokine analysis and clinical correlations in evaporative-type dry eye disease. Mol Vis. 2010;16:862-873.

24. Jampel HD, Quigley HA, Kerrigan-Baumrind LA, Melia BM, Friedman D, Barron Y; Glaucoma Surgical Outcomes Study Group. Risk factors for late-onset infection following glaucoma filtration surgery. Arch Ophthalmol. 2001;119(7):1001-1008.

25. Yamamoto T, Kuwayama Y; Collaborative Bleb-related Infection Incidence and Treatment Study Group. Interim clinical outcomes in the collaborative bleb-related infection incidence and treatment study. Ophthalmology. 2011;118(3):453-458.

26. Wang J, Aquavella J, Palakuru J, Chung S. Repeated measurements of dynamic tear distribution on the ocular surface after instillation of artificial tears. Invest Ophthalmol Vis Sci. 2006;47(8):3325-3329.

27. Palakuru JR, Wang J, Aquavella JV. Effect of blinking on tear dynamics. Invest Ophthalmol Vis Sci. 2007;48(7):3032-3037.
Clinical Ophthalmology

\section{Publish your work in this journal}

Clinical Ophthalmology is an international, peer-reviewed journal covering all subspecialties within ophthalmology. Key topics include: Optometry; Visual science; Pharmacology and drug therapy in eye diseases; Basic Sciences; Primary and Secondary eye care; Patient Safety and Quality of Care Improvements. This journal is indexed on Submit your manuscript here: http://www.dovepress.com/clinical-ophthalmology-journal

\section{Dovepress}

PubMed Central and CAS, and is the official journal of The Society of Clinical Ophthalmology (SCO). The manuscript management system is completely online and includes a very quick and fair peer-review system, which is all easy to use. Visit http://www.dovepress.com/ testimonials.php to read real quotes from published authors. 